\title{
Changes in the percentage of 5-year-old children with no experience of decay in Dudley towns since the implementation of fluoridation schemes in 1987
}

\author{
M. M. Gray, ' and J. Davies-Slowik, ${ }^{2}$
}

Objective To compare changes in dental health between nonfluoridated Stourbridge and the towns of Dudley, Sedgeley and Coseley, Brierley Hill and Kingswinford, and Halesowen that were artificially fluoridated in 1987

Basic research design BASCD co-ordinated studies of total samples of 5-year-old children

Clinical settings State funded primary schools in the Dudley Health Authority area

Participants All 5-year-old children present on the day of examination in the years in which total population studies were conducted

Interventions Drinking water fluoridation commenced in 1987 Main outcome measure The percentage of children with no experience of decay in their primary dentition

Results The percentage of children with no experience of decay in the fluoridated towns increased but remained the same in nonfluoridated Stourbridge

Conclusion Drinking water fluoridation is associated with an increase in the percentage of 5-year-old children with no experience of tooth decay

$\mathrm{D}$ dley Health Authority Area comprises a group of small towns, including Dudley, Halesowen, Stourbridge, Kingswinford and Brierley Hill and Sedgley and Coseley. It has borders with midStaffordshire in the west, with Wolverhampton to the north, with Sandwell, and Birmingham to the east and Worcestershire to the south. Historically, Dudley has been a base for heavy industry, however with progressive decline of this industrial base, in recent years, there is extensive deprivation particularly in the east (Dudley town) and in the north (Coseley) of the district.

The population of Dudley has remained constant over the past 15 years and socio-economic profile and ethnic mix of the district has changed little. The population is served by 80 General Dental Practitioners working from 40 dental practices.

Following public consultation water fluoridation at 1 part per million was implemented in all parts of the Dudley Health Authority area served by South Staffs Water Company in 1987. This

\footnotetext{
${ }^{* 1}$ Consultant in Dental Public Health, Dudley Health Authority, Bull Street, Dudley, UK ${ }^{2}$ Clinical Director, Community Dental Service, Dudley Priority Health NHS Trust, Westhill Clinic, Hagley Road, Stourbridge, UK

${ }^{\star}$ Correspondence to: Dr M. Gray, 3 Sycamore Way, Market Bosworth, Nuneaton, Warwickshire CV13 OLU\}

email: margaret_mary_gray@hotmail.com

REFEREED PAPER

Received 19.06.00; Accepted 23.08.00

(C) British Dental Journal 2001; 190: 30-32
}

included the towns of Dudley, Sedgley and Coseley, Brierley Hill and Kingswinford, and Halesowen. The town of Stourbridge receives its drinking water from Severn Trent and was not fluoridated in 1987, the drinking water in Stourbridge has only low background levels of fluoride (under $0.3 \mathrm{ppm}$ )

Surveys of the dental health of Dudley children have been conducted every other year since 1986. These surveys have been conducted under the auspices of the British Association for the Study of Community Dentistry (BASCD) Dental Epidemiology programme and contribute to national monitoring of the dental health of children in addition to providing local data for service planning, local oral health strategy and Health Improvement Plan (HImP) development.

\section{Method}

Total population samples of 5-year-old children were examined in the school years 1988/89, 1992/93 and 1996/97. The examinations

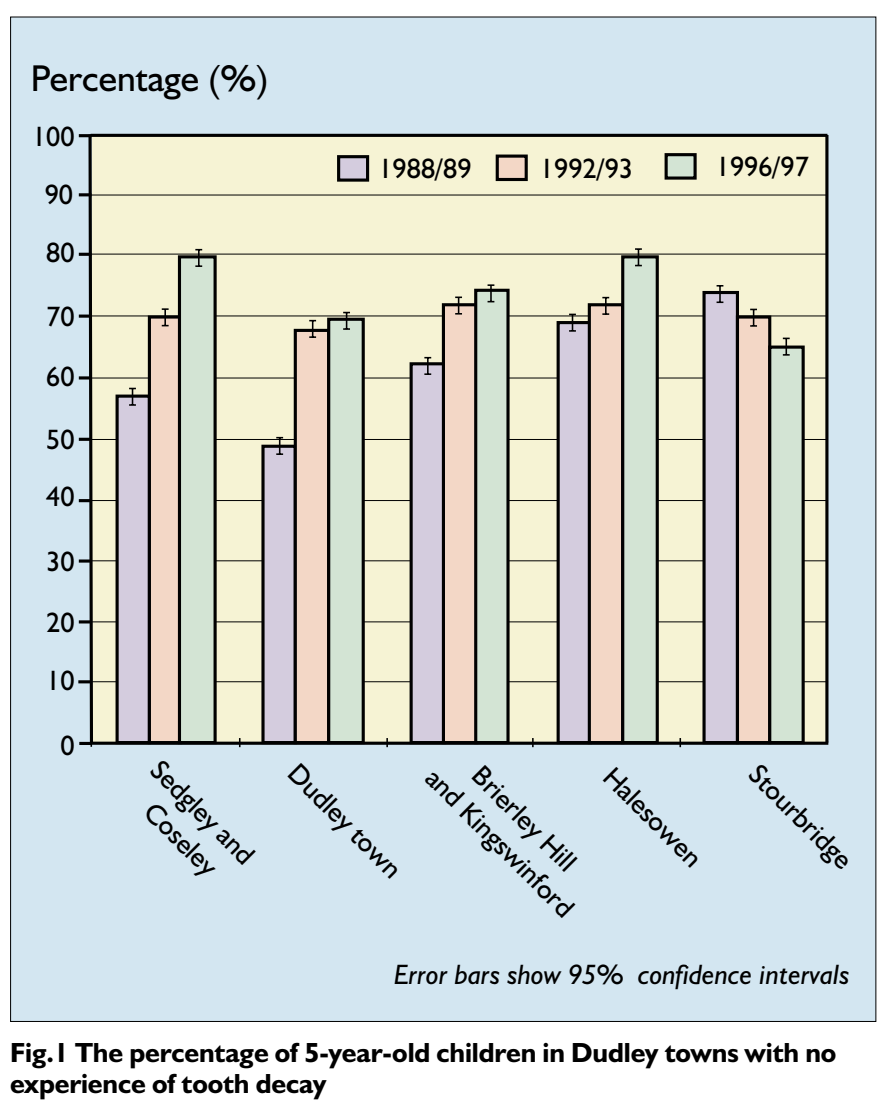


Table I Breakdown of the sample between Dudley towns

\begin{tabular}{l|c|c|c|c|c}
\hline \multirow{2}{*}{ Survey year } & \multicolumn{4}{|c|}{ Town } & \multirow{2}{*}{ Stourbridge } \\
\cline { 2 - 5 } & Sedgley and Coseley & Dudley town & $\begin{array}{c}\text { Brierley Hill and } \\
\text { Kingswinford }\end{array}$ & Halesowen & \\
\hline $1988 / 89$ & $537(18.3 \%)$ & $552(18.9 \%)$ & $826(28.2 \%)$ & $547(18.7 \%)$ & $466(15.6 \%)$ \\
$1992 / 93$ & $565(19.0 \%)$ & $580(19.5 \%)$ & $774(26.0 \%)$ & $580(19.5 \%)$ & $476(16.0 \%)$ \\
$1996 / 97$ & $475(16.1 \%)$ & $594(20.2 \%)$ & $891(30.3 \%)$ & $564(19.2 \%)$ & $419(14.2 \%)$ \\
\hline
\end{tabular}

Table 2 The number and percentage of children in Dudley towns with no experience of decay

\begin{tabular}{|c|c|c|c|c|c|c|c|c|c|c|}
\hline & \multicolumn{2}{|c|}{ Fluoridated } & \multicolumn{2}{|c|}{ Fluoridated } & \multicolumn{2}{|c|}{ Fluoridated } & \multicolumn{2}{|c|}{ Fluoridated } & \multicolumn{2}{|r|}{ Not fluoridated } \\
\hline Town & \multicolumn{2}{|c|}{ Sedgley and Coseley } & \multicolumn{2}{|c|}{ Dudley town } & \multicolumn{2}{|c|}{$\begin{array}{l}\text { Brierley Hill and } \\
\text { Kingswinford }\end{array}$} & \multicolumn{2}{|c|}{ Halesowen } & \multicolumn{2}{|r|}{ Stourbridge } \\
\hline Survey year & $n$ & $\%$ & $n$ & $\%$ & $n$ & $\%$ & $n$ & $\%$ & $n$ & $\%$ \\
\hline $\begin{array}{l}1988 / 89 \\
1992 / 93 \\
1996 / 97\end{array}$ & $\begin{array}{l}306 \\
396 \\
379\end{array}$ & $\begin{array}{l}57.0(56.5,59.2) \\
70.0(69.7,72.2) \\
79.8(79.4,82.0)\end{array}$ & $\begin{array}{l}270 \\
394 \\
413\end{array}$ & $\begin{array}{l}49.0(48.4,51.3) \\
68.0(67.5,70.2) \\
69.5(69.1,71.7)\end{array}$ & $\begin{array}{l}512 \\
557 \\
660\end{array}$ & $\begin{array}{l}62.0(61.6,64.2) \\
72.0(71.6,74.2) \\
74.1(73.8,76.2)\end{array}$ & $\begin{array}{l}377 \\
418 \\
451\end{array}$ & $\begin{array}{l}69.0(68.5,71.2) \\
72.0(71.6,74.2) \\
80.0(79.6,82.2)\end{array}$ & $\begin{array}{l}345 \\
333 \\
273\end{array}$ & $\begin{array}{l}74.0(73.5,76.2) \\
70.0(69.5,72.2) \\
65.2(64.6,67.5)\end{array}$ \\
\hline \multicolumn{2}{|c|}{$\begin{array}{l}\text { Change in } \\
\text { percentage between } \\
\text { 1988/89 and 1996/97 }\end{array}$} & $+22.8(20.2,25.5)$ & & $+20.5(17.8,23.3)$ & & $+12.1(9.6,14.7)$ & & $+11.0(8.4,13.6)$ & & $-8.8(-11.6,-6.1)$ \\
\hline
\end{tabular}

$95 \%$ Confidence intervals are shown in parenthesis

were conducted to a common protocol ${ }^{1}$ by examiners and recorders who were trained and calibrated to West Midlands regional standards in the collection and recording of caries data. Dental caries in all the reported surveys was diagnosed at the caries into dentine threshold. Diagnosis of caries was visual without the use of radiographs, trans-illumination or compressed air. The examiners were members of staff of the Community Dental Service in Dudley and as such were aware of the fluoridation status of the areas included in this study and blinding was not possible. Sample surveys of under $50 \%$ of the 5 -year-old population conducted in intervening years have been excluded from these comparisons as the numbers in the sub-groups were low. The outcome measure used in this comparison is the percentage of children with no experience of decay measured using the $\mathrm{dmft}$ index ie those children with a dmft score of zero. Children were allocated to each of the towns on the basis of the location of the school they attended, for the surveys conducted in 1988/89 and 1992/93, and on the basis of their home postcode in the 1996/97 survey.

\section{Results}

There was little variation in the numbers of children examined in each of the reported survey years. The number and percentage of children examined in each of the towns is listed in Table 1. The number and percentage of children with no experience of dental decay increased markedly in the fluoridated towns and declined in non-fluoridated Stourbridge (Table 2 and Fig. 1). The increase in the percentage of children with no experience of decay in the fluoridated towns and the decrease in non-fluoridated Stourbridge is shown in Figure 2. The percentage of children reaching the age of 5 years with no experience of dental caries in their primary teeth has increased since the introduction of fluoridation in Sedgley and Coseley, Dudley town, Brierley Hill and Kingswinford, and Halesowen. In Stourbridge, where there has been no artificial or natural fluoridation the percentage of children reaching the age of five without experiencing tooth decay has reduced. All these changes are statistically significant and fall well outside $95 \%$ confidence intervals.

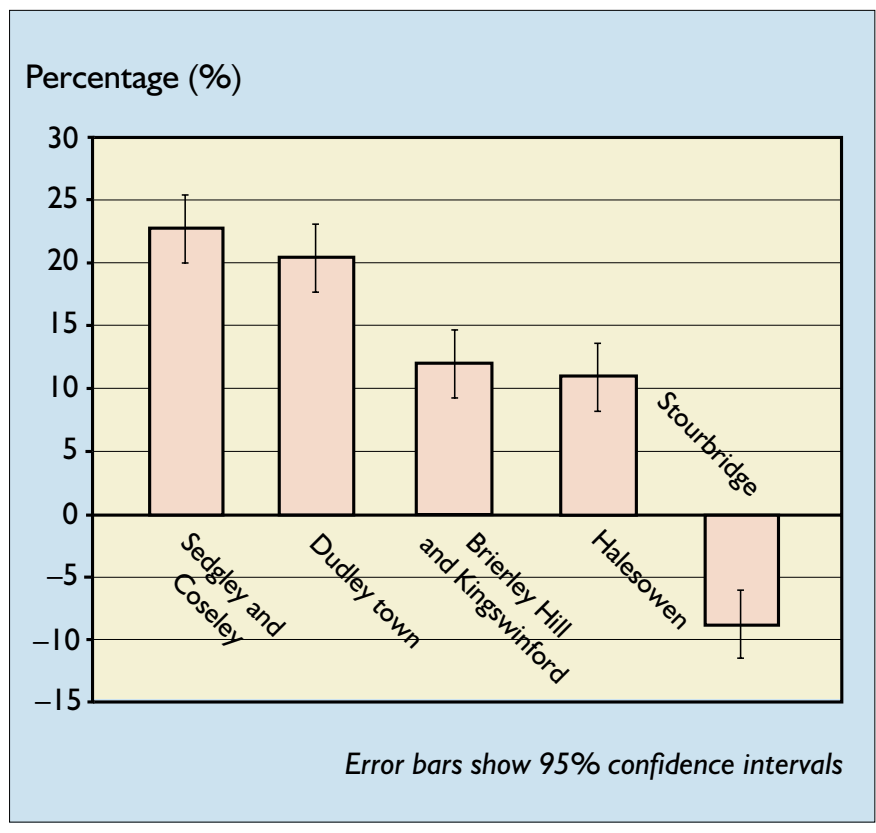

Fig. 2 Changes in the percentage of 5-year-old children with no experience of tooth decay in Dudley towns between 1998 and 1996

\section{Discussion}

These studies were not conducted blind as the examiners were aware of the fluoridation status of the areas in which the children attended schools, however the examiners were trained in examination techniques and their reproducibility was tested in calibration exercises. The passage of time and the increasing sophistication of the computer systems used to collate and analyse the data has resulted in the loss of some of the information and the raw data from the 1988/89 study. As a result it is only possible to report on the percentage of children who were caries free within 1 year of introduction of fluoridation on a sub-district basis, although other measures of the dental health are still available for the district as a whole. The location of 


\section{RESEARCH water fluoridation}

the school attended by children, was used in the 1988/89 and the $1992 / 93$ studies as the basis for allocating children to each of the towns. This is not an ideal basis, as children may live in one area and attend school in a neighbouring area and there will be some cross boundary flow in the two earlier studies. In the most recent study (1996/7) children were allocated to each of the towns on the basis of their residential postcode, in order to eliminate any inaccuracies and to increase the robustness of the data. In spite of the different methodology for allocating the children to localities in the third survey, the percentage of the total sample from each of the localities for each of the survey years is similar.

Although the change in methodology in the third survey is a possible source of error the consistent pattern of the results, both geographically and over time, indicates a lack of bias even though there were minor changes in methodology. It is clear that the number and percentage of children with no experience of dental decay has significantly increased in those towns that were fluoridated in 1987 but not in Stourbridge which has not been fluoridated yet. As a result in three of the fluoridated town, Sedgley and Coseley, Brierley Hill and Kingswinford, and Halesowen the National Objective that by $2003,70 \%$ of 5 -year-old children should have no caries experience has already been achieved. This finding is in line with the results of BASCD surveys conducted in the neighbouring and similar districts of Walsall and Sandwell, where fluoridation was also introduced in 1987 and the percentage of children with no decay experience has increased by $17 \%$ and $18 \%$ respectively over the same time period. ${ }^{2}$ Other similar studies of 5-year-old children living in areas in which fluoridation has been introduced ${ }^{3-5}$ also show similar improvements in dental health.

The authors are grateful to the staff and pupils of Dudley MBC primary schools who participated in these surveys and to the fieldwork staff of Dudley Priority Services Community Health Trust who collected the data.

1 Pitts N B, Evans D J, Pine C. British Association for the Study of Community Dentistry (BASCD) diagnostic criteria for caries prevalence studies - 1996/7. Community Dental Health 1997; 14 (Supplement 1): 6-9.

2 Nugent Z J, Pitts N B. Patterns of change and results overview 1985/61995/6 from the British Association for the Study of Community Dentistry (BASCD) co-ordinated National Health Service surveys of Caries Prevalence. Community Dental Health 1997; 14: 30-54.

3 Beal J, James P. Dental caries prevalence in 5-year-old children following five and a half years of water fluoridation in Birmingham. Br Dent J 1971; 130: 284.

4 Beal J, Clayton M. Fluoridation in a clinical survey in Corby and Scunthorpe. England UK Public Health (Lond) 1981; 95: 152-160.

5 Kunzel W, Fischer T. Rise and fall of caries prevalence in German towns with different $\mathrm{F}$ concentrations in drinking water. Caries Res 1997; 31: 166-173. 